Article

\title{
Enabling Value Co-Creation in the Sharing Economy: The Case of Mobike
}

\author{
Jing Lan ${ }^{1}$, Yuge Ma ${ }^{2}{ }^{*}$, Dajian Zhu ${ }^{1}$, Diana Mangalagiu ${ }^{2,3}$ and Thomas F. Thornton ${ }^{2}$ \\ 1 School of Economics and Management, Tongji University, Shanghai 200092, China; \\ pooher2222@163.com (J.L.); dajianzhu@263.net (D.Z.) \\ 2 Environmental Change Institute, University of Oxford, Oxford OX1 3QR, UK; \\ diana.mangalagiu@ouce.ox.ac.uk (D.M.); Thomas.thornton@ouce.ox.ac.uk (T.F.T.) \\ 3 NEOMA Business School, 76130 Mont-Saint-Aignan, France \\ * Correspondence: yuge.ma@ouce.ox.ac.uk; Tel.: +44-7402798035
}

Received: 23 July 2017; Accepted: 21 August 2017; Published: 24 August 2017

\begin{abstract}
The disruptive rise of the sharing economy has inspired multiple social innovations embodying significant potential towards achieving urban sustainability in crucial areas like low-carbon mobility. Increasingly, consumers in such sharing systems participate in activities of value co-creation together with firms and peers, such as through enforcing rules that help maintain trust and reciprocity. Why do people choose to invest their time and energy in co-creating values that may benefit wider social and environmental sustainability in the sharing economy? This study addresses this question through an analysis of an emerging shared mobility community, the innovative socio-economic relationships it has spawned, and the cultural and cognitive forces that underpin these new forms of economic organization and value creation in relation to sustainability. Through a mixed method case study of a newly emerged free-floating bike sharing system in China, called Mobike, the paper explores the main enabling factors which is transforming people from passive product/service receivers to active value co-creators in the sharing economy, such as self-efficacy, cognition of duty, anticipated awards and learning processes. The paper argues that business, social and government organizations may leverage these enabling factors to achieve a more sustainable sharing business and society. Finally, based on quantitative and qualitative data analysis, the article proposes a value co-creation framework between users and firms that involves a clear social learning process on the one hand, and has strong links with social innovations towards sustainability, on the other.
\end{abstract}

Keywords: value co-creation; sharing economy; business models; sustainability; bike sharing; prosumption; social learning; social innovation; behavior; Mobike

\section{Introduction}

Technological and commercial advances in recent years have expanded the scope of the sharing economy from mainly existing in the digital world (e.g., knowledge, music and movie sharing websites) to increasing involvement with the physical world (e.g., home-sharing, office-sharing, car-sharing, and bike-sharing) [1-4]. The Online to Offline (O2O) move is an important characteristic of the sharing economy today, potentially contributing to solving or enhancing the environmental and social challenges of the Anthropocene. The sharing economy provides a very direct way for urban citizens to imagine alternative urban lifestyles $[5,6]$. The growing number of commercial and social practices and experiments using sharing economy business models (BMs) are affecting urban economies and lifestyles on an increasingly deep and large scale $[7,8]$. For example, access-based rather than ownership-based consumption as a result of such BMs is cheaper and easier to maintain, and have lower ecological footprints for the same levels of human needs $[9,10]$. 
At the same time, the rapid development of the sharing economy has inspired different modes of social innovation, especially at the grassroots level, where people take advantage of various sharing BMs to help solve social-environmental problems, such as promoting sustainable consumption and production practices [11]. In this way, the public co-creates values that contribute to sustainable urban living with each other and with sharing businesses. Therefore, social innovations play a key role in enabling sharing BMs to fulfil its sustainability potentials through novel modes of value co-creation between firms and users.

Using the case of a newly emerged free-floating bike sharing (FFBS) system in China, called Mobike, we investigate why people participate in value co-creation activities with sharing firms/organizations. Building on this empirical enquiry, we propose a framework to conceptualize this emerging form of value co-creation enabling social innovations towards urban sustainability in the sharing economy. This article is organized as follows: Section 2 lays out the theoretical context of value co-creation and social innovation in the sharing economy using the concept of prosumer; Section 3 elaborates the mixed method case study in detail; Section 4 presents the empirical results; Section 5 discusses the research question based on empirical data, and Section 6 concludes and outlines limitations and further research.

\section{Prosumer, Value Co-Creation and Social Innovation in the Sharing Economy}

Traditionally, consumption and production systems have been treated as discrete streams [12]. The increasingly widespread Internet and digital technologies have changed the consumer-producer relationship dramatically, largely because technologies have empowered consumers to create, collaborate, produce and contribute to commercialisation by considerably lowering the cost of value co-creation [13], in some cases to near zero marginal cost [14]. In the context of the sharing economy, many shared products and services are often co-produced by producers and consumers, blurring the boundaries between consumers and firms, consumers and peers, and between consumers and labor (individual producers) [12,15-17].

We borrow the concept of prosumer/prosumption to describe the mesh of consumer-producer roles of value co-creation in the context of the sharing economy. From the Industrial Revolution until the late-twentieth century, consumers played a rather passive role in capitalist production [18]. "Prosumption" was first coined in the 1980s as an umbrella word to describe the then emerging phenomenon of consumers" "do-it-yourself" activities [19]. The prosumption concept has since been advanced by scholars in consumer studies [20] and socio-economic studies [16,21-23]. Ritzer [16] define prosumption as a continuum of relations involving both producers and consumers in the co-creation of goods and services. As Figure 1 shows, prosumers may input their spare capacities (labor, intellectual capital and physical capital) into the possible value co-creation spaces with firms to carry out design, manufacturing, distribution, and other critical processes. In this prosumption process, the dual roles of prosumers become intertwined in active value co-creation. The rising importance of prosumers' value co-creation activities has led firms to leverage this as a key source of competitive advantage - to understand and satisfy consumers' needs on the one hand [21,24], and to benefit companies commercial interests on the other $[25,26]$.

Value co-creation provides collaboration opportunities between suppliers and consumers to obtain more values during possible spaces and processes [26]. Vargo and Lusch [24] argued that firms give value propositions for consumers to respond to as prosumers in order to achieve reciprocal service provision. In this way, both firms and consumers integrate their resources effectively to respond to each other's needs. Also, Vargo and Lusch [27] argued that value must be co-created in a certain context because value co-creation activities are embedded in and (re)configured by certain social structures and networks [28]. 


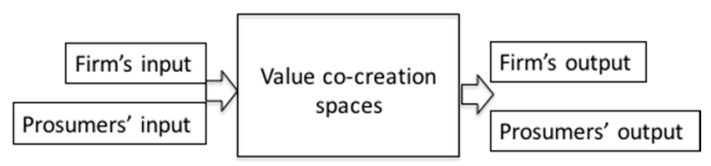

Figure 1. Firm and prosumer's value co-creation process [29].

Value co-creation between firms and prosumers has evolved further in the context of the sharing economy. On the one hand, there are multiple roles and duties for prosumers to choose from, such as sharing their idle goods and spare capacities as a producer or accessing goods and services as a consumer [22]. On the other hand, prosumers' value co-creation behavior is more ubiquitous and pivotal in the sharing economy compared with traditional BMs [29]. This is because, in a highly-connected sharing market, the sense of reciprocity and community belonging is not only instrumental to market promotion, but also essential for maintaining the network effects, ensuring positive usage outcome, sustaining active participation, and preventing participants' misbehavior [30]. Some researchers argue that users in the sharing systems are prone to abuse rules or misbehave-engaging in theft, vandalism, and free riding, for example-through deliberately acting against the commonly accepted or set rules, or taking advantage of loopholes in the system and damaging trust [31,32]. Therefore, regulation of users toward sustainable value co-creation behavior is crucial to mitigate possible negative actions, manage the commercial sharing systems effectively and improve the welfare of the whole community [33-35]. Moreover, encouraging and appropriating prosumers' value co-creation in sharing businesses can generate a wider socioeconomic impact because the sharing economy is increasingly tied to provisioning essential needs in people's daily lives, such as mobility, accommodation and food.

This special issue is focused on novel theoretical and empirical studies of social innovation and value co-creation. Given prosumers' increasingly important role in sharing businesses that provide solutions to social problems, such as insufficient social services, we consider the value co-creation between prosumers and sharing businesses an emerging social innovation. This innovation is contributing to 'identifying and implementing new competencies and new forms of participation, collaboration, and relationships among individuals and organizations to produce solutions' as themed in this special issue. In addition, prosumers' value co-creation is proving essential for sharing businesses to realize their social transformation potential in providing better quality of life, such as more convenient, efficient and green daily transport for urban dwellers. Therefore, value co-creation between prosumers and firms is not only a form of social innovation in itself, but also a key channel to realize the potential of the sharing economy in transforming cities towards sustainability.

However, it is not always clear why prosumers invest their time, energy, intellectual capital and sometimes financial and physical capital in such value co-creation activities. Profit is one motive, to be sure, but in many cases there are additional commitments, including social and cultural capital, which pay dividends through the prosumption process. Recent studies have analyzed the factors affecting users' sharing behavior, such as their social, economic and environmental motivation [10,36-38]. Some of these studies focus on the passive roles played by prosumers that could be ascribed to having no other available career options [39], or mostly pursuing monetary incentives [40]. Such studies tend to critique the monopolizing power of the sharing platforms, which mediate social-economic relations, as a tool to maximize profits at the expense of individuals' free will and welfare [41,42]. While recent studies show that an increasing number of prosumers are participating actively and voluntarily in the sharing economy's value co-creation which may contribute to wider social and environmental sustainability [43], such behaviors, and the key factors enabling them, are understudied.

Nevertheless, understanding the motivations for prosumers' active value co-creation behavior is crucial for enabling and encouraging emergent patterns of social innovations to thrive in the sharing economy [44], and for realizing its sustainability potentials in key areas of human consumption, such 
as food, accommodation, and transport systems. In this article, we attempt to explore this important yet under researched topic using a case study as elaborated below.

\section{Methods and Data}

We choose Mobike, an influential free-floating bike sharing (FFBS) system as an instrumental case study [45] to conduct in-depth analysis of the real-life factors enabling prosumers' active value co-creation behavior in the sharing economy. FFBS is ideal to serve this explorative research goal for three reasons: first, it is a novel and fast developing BM in the sharing economy, generating huge impact on transport in urban areas of China and beyond [46]; second, users play several significant roles as prosumers in the FFBS; and third, the prosumption process in the FFBS can be divided into distinct developmental phases, supporting quantitative investigation of cognitive changes in value co-creation behavior in different phases of their involvement with the business. In this section, we first outline the case study context (Section 3.1) and then the mixed method used (Section 3.2).

\subsection{Case Study Context}

\subsubsection{The Development of FFBS}

The first urban-scale bike-sharing scheme, known as "White Bikes", was launched in Amsterdam in July 1965. Bicycles were left unlocked, and parked casually throughout an area for free use. However, the "White Bike Plan" failed soon after its launch due to costs and issues of theft and unreliable distribution. The first pay-as-you-go bike-sharing scheme (using a coin-deposit system) was launched in Copenhagen in January 1995. Called "Bycyklen", this scheme introduced docking stations and deposits to the bike-sharing model. In 1998, a third-generation of bike-sharing scheme came on line, incorporating information technology that allowed the provider to track bicycles and user information, in order to deter bike theft and optimize bike allocation [47]. Over the past two decades, over 855 cities have implemented third-generation bike-sharing programs around the world, with most supported by local governments [48].

The FFBS began in 2016 in China as a fourth generation bike-sharing start-up. It is a bike rental service with no docking stations; rather, each bike contains a microchip that enables the unit to be located anywhere within the cities' government-planned bike parking areas using a mobile phone-based app. Similar systems exist in Germany (CallaBike), in the USA (SocialBike) and in Denmark [49-51]. Generally, the bike is equipped with a unique Location Based Service (LBS) system, electric generation equipment and theft prevention mechanisms. Through the mobile app, users can unlock the bike and the fee is charged automatically depending on time of use. This scheme frees bikes from limitations of fixed docking stations, providing a much more convenient service than the traditional public bike-sharing system.

\subsubsection{Mobike and Value Co-Creation Behavior}

Mobike has emerged as a phenomenal company [46]; having initiated the first FFBS in Shanghai on 22 April 2016, by July 2017, the company was serving around 100 million registered users in China, England, Japan and Singapore. Mobike aims to operate in 200 cities globally by the end of 2017 . The company designs and manufactures its own bikes, and claims to have abandoned the traditional concept of "bikes" and embraced the philosophy of "smart" auto-mobility in its vehicle design. In contrast to the traditional bike, Mobike's vehicles aim for durability (4+ years) and all-weather riding (Solid aluminum body) which, the company claims, support circular economy principles of reducing the carbon footprint of the bike's product life cycle. Through its LBS, electric generation equipment, smart lock and theft prevention mechanisms, users can securely locate and reserve bikes 15 min in advance, and scan a bike's QR (Quick Response) code to unlock it. After use, riders simply park the bike anywhere within the city's designated public bike parking places beside the main road. In this way, the service provider needs no docking stations, and, assuming riders comply with parking 
rules, other users can easily find the nearest bike to their location. Users pay a deposit of $299 \mathrm{CNY}$ (43 USD) when registering through the app, and a user fee of 1 CNY (0.15 USD) per $30 \mathrm{~min}$ in China.

Despite its "smart" bikes designed for sharing use, Mobike's operation has encountered several challenges. First, even smart bikes break down and thus the company faces challenges to maintain it vast fleet; not attending to breakdowns in a timely manner can result in injury, delay or other bad experiences for riders. Second, broken bikes may be widely distributed in different locations around the city, making it a challenge and both a material and labor cost to fix or replace them in a timely manner. Finally, some Mobike users ignore the parking rules and park the bikes in private places instead of public areas, making it difficult for other users to find or access them, and a potential further labor cost to recover them.

To guide and incentivize users' value co-creation behavior towards amelioration of these issues and better support the FFBS scheme, Mobike implemented a credit-scoring system for users' self-regulation, and reporting of other users' violations of the rules (Figure 2). The credit scheme both rewards good sharing behavior, such as photographing and reporting broken bikes, and punishes bad sharing behavior, such as inappropriate parking. Every registered user is issued 100 Mobike credits initially; but if the user's credit is lowered (by deduction for violation of the rules) to less than 80 , their rental rate for the scheme rises to 100 CNY (15 USD) per half hour. Alternatively, a user who enhances the system by reporting broken or misparked bikes, may earn credits above 100 to put towards the price of future Mobike rentals.

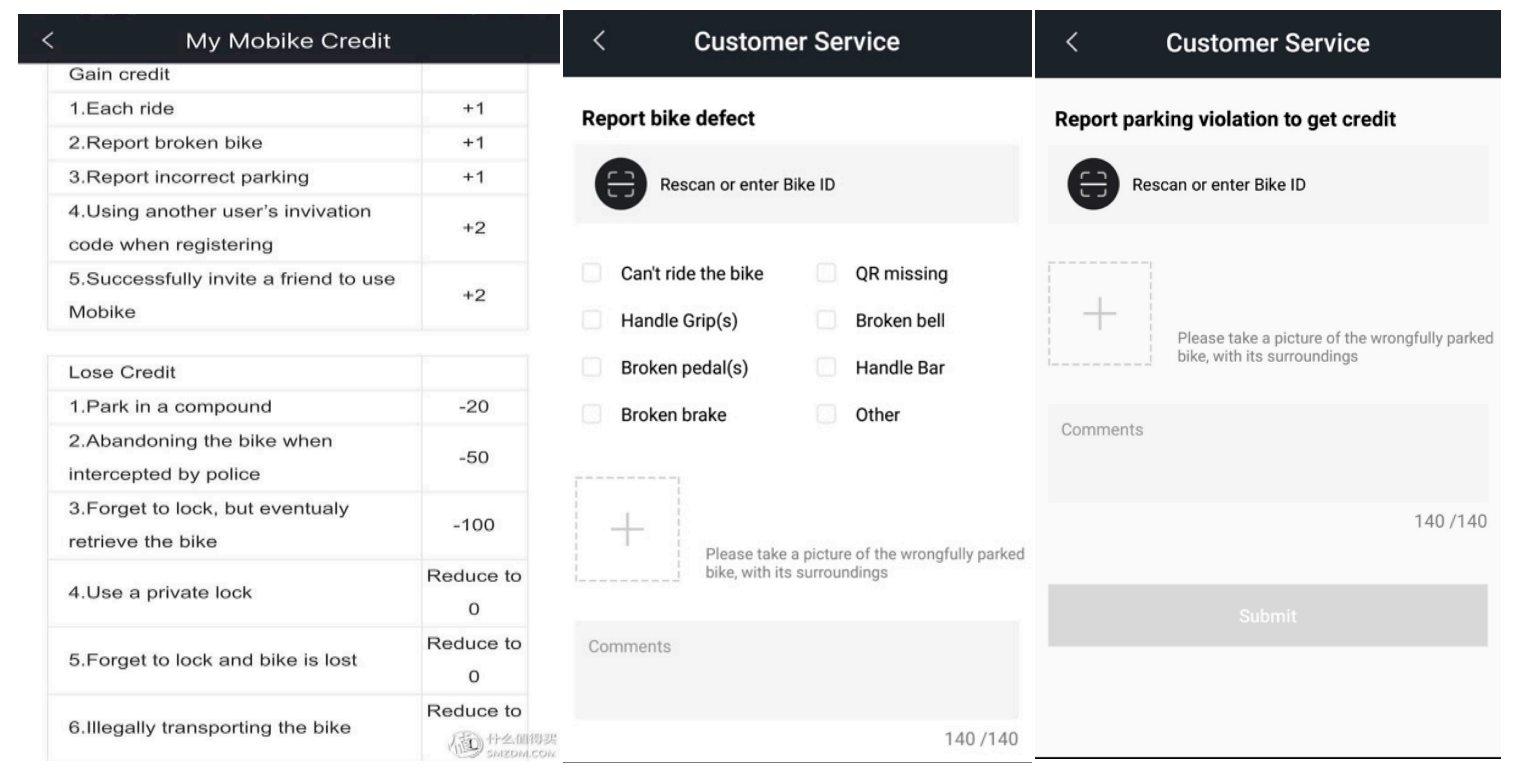

Figure 2. Mobike's credit-scoring system to incentivize value co-creation behavior.

Thus, in the FFBS, service providers require extensive value co-creation from users as value co-creators/prosumers [33], involving a higher level of consumer contribution than in traditional docking bike-sharing systems. As illustrated in Table 1, Mobike user A plays the role of value co-creator at every step. In particular, users are supposed to park the bikes in zoned places according to the usage rules. Illicit parking behavior, however, is difficult to monitor and occurs in the absence of Mobike's employees and other users. It is difficult to establish accurate self-reporting information at the return stage. In this context, Mobike encourages users toward "reporting the bike defection" and "reporting the parking violation" through the app system, thus engendering specific and active value co-creation behaviors that help both the company and consumer community maintain and improve the sharing system in the FFBS. 
Table 1. Mobike Company and user's value co-creation process.

\begin{tabular}{|c|c|c|c|c|c|}
\hline \multirow{2}{*}{$\begin{array}{r}\text { Value Co-Creation } \\
\text { Spaces }\end{array}$} & \multicolumn{4}{|c|}{ User Process } & \multirow{2}{*}{$\begin{array}{c}\text { Reporting } \\
\text { Process }\end{array}$} \\
\hline & Finding a Bike & Placing and Unlocking & Riding & Return & \\
\hline \multirow{3}{*}{ Service provider } & Mobike Company & Mobike Company & \multirow{3}{*}{$\begin{array}{l}\text { Mobike } \\
\text { Company }\end{array}$} & $\begin{array}{l}\text { Mobike } \\
\text { Company }\end{array}$ & User A \\
\hline & The last user & User A & & User A & $\begin{array}{l}\text { Mobike } \\
\text { Company }\end{array}$ \\
\hline & User A & & & & \\
\hline \multirow[b]{2}{*}{ Service obtainer } & \multirow[b]{2}{*}{ User A } & \multirow[b]{2}{*}{ User A } & \multirow[b]{2}{*}{ User A } & The next user & Users \\
\hline & & & & $\begin{array}{c}\text { Mobike } \\
\text { Company }\end{array}$ & $\begin{array}{c}\text { Mobike } \\
\text { Company }\end{array}$ \\
\hline Potential issues of devaluation & $\begin{array}{l}\text { Difficulties to find a } \\
\text { bike, Defective bike }\end{array}$ & Defective App & Illegal riding & $\begin{array}{l}\text { Defective App } \\
\text { Illegal parking }\end{array}$ & $\begin{array}{c}\text { User's } \\
\text { participation }\end{array}$ \\
\hline
\end{tabular}

In summary, value co-creation in the case of Mobike is realized when users voluntarily and consistently follow the rules of the sharing system, while at the same time report on failures or misuse, such as defective bikes or wrongful parking. Compared with the general Mobike user process, reporting behavior is a more active and independent value co-creation activity that deliberately helps the system function more responsively for those who rely on it, building trust and reciprocal values towards the maintenance of the sharing economy. We therefore employ reporting behavior as a proxy representing prosumer's value co-creation to conduct the empirical research as elaborated below.

\subsection{Mixed Methods}

In this exploratory study, we investigate Mobike users' active value co-creation behaviors and enabling factors through a two-stage mixed method analysis. Firstly, using non-participant observation and semi-structured interviews $(n=21)$, we identify five key factors enabling prosumers active value co-creation in Mobike (Section 3.2.1). Secondly, we test the identified factors by logit regressions, using an online survey $(n=457)$ (Section 3.2.2).

\subsubsection{Stage One: Qualitative Exploration}

Qualitative methods are utilized to gain a theoretical explanation of emergent patterns through a hermeneutic and iterative analysis of the phenomenon, providing insights and integrated theory in the next quantitative stage [52].

Before collecting interview data, systematic non-participant observations of Mobike's operations were conducted between July to November in 2016 in Shanghai, the first Mobike pilot city, in order to gather first-hand information on how the system works, the interaction between the system and users, and the regulations involving value co-creation behavior. This provided a holistic view of the system and constructive guidance for further interviews [53]. Then, in-depth semi-structured interviews were conducted in November and December 2016, in Shanghai with 21 Mobike's users to investigate the reasons for their participation in value co-creation.

Interviewees were selected for their active and voluntary participation in helping Mobike through investing their time, energy and sometimes money to report and regulate misbehaviors. All of the 21 interviewees $(71 \%$ male, Mean age $=34$, ranging between 19 and 50) had more than three months' experience using the system to ensure that they were well acquainted with various situations experienced using Mobikes. Male responders made up the majority of this sample, because they expressed more active value co-creation and were willing to share their experiences.

Two different interview methods were used: face-to-face interviews with eight interviewees, and online interviews with 13 participants. The interviews explored prosumers' rationales for value co-creation and their specific interactions with the system and other users. Questions were centered around "reasons of participation in the reporting activities on Mobike" and "the cognitive changes and 
interaction processes in the reporting processes." Iterative analysis ended when theoretical saturation was reached.

\subsubsection{Stage Two: Quantitative Factors}

To generalize the identified enabling factors of value co-creation behavior from interviews, a quantitative study was conducted. An online survey was set using a paid for service at www.sojump.com, a popular Chinese survey website in December 2016 and January 2017. The online survey link was shared and forwarded to Mobike's users on WeChat, the dominant Chinese social media platform, with a 3 CNY reward for each completed questionnaire. After assessing the surveys, we excluded the questionnaires that reported not having Mobike user experience or not having encountered issues such as bike defects and parking violations. We also excluded the questionnaires with incompatible answers to the two questions "which value co-creation behaviors have you participated in?" and "have you participated in value co-creation behaviors?" This audit yielded 457 valid questionnaires for quantitative analysis from the original 668. Valid questionnaires' demographic information can be found in Table 2. We compared the surveyed participants' and the Mobike users' demographics (gender and age) in Shanghai to ensure that valid questionnaires could represent the diverse population of Mobike users in Shanghai.

Table 2. Participant demographics in the second stage.

\begin{tabular}{|c|c|c|}
\hline \multirow{2}{*}{ Variables } & \multirow{2}{*}{ Categories } & Percentage (\%) \\
\hline & & Stage $2(n=457)$ \\
\hline \multirow{2}{*}{ Gender } & Male & 52.08 \\
\hline & Female & 47.92 \\
\hline \multirow{8}{*}{ Age } & $16-18$ & 2.84 \\
\hline & $19-25$ & 26.48 \\
\hline & $26 \sim 30$ & 33.26 \\
\hline & $31 \sim 40$ & 29.98 \\
\hline & $41 \sim 50$ & 4.60 \\
\hline & $51 \sim 60$ & 1.75 \\
\hline & $>60$ & 1.09 \\
\hline & Mean/SD & $29.83 / 4.27$ \\
\hline \multirow{2}{*}{ Married } & Yes & 43.11 \\
\hline & No & 56.89 \\
\hline \multirow{2}{*}{ Children } & Yes & 31.95 \\
\hline & No & 68.05 \\
\hline \multirow{4}{*}{ Education } & Up to secondary school & 3.28 \\
\hline & High school & 10.07 \\
\hline & Bachelor's degree or some college & 79.43 \\
\hline & Graduate degree & 7.22 \\
\hline \multirow{6}{*}{ Income (yearly, CNY) } & $<30,000$ & 14.88 \\
\hline & 30,000 to 60,000 & 21.01 \\
\hline & 60,000 to 150,000 & 40.26 \\
\hline & 150,000 to 250,000 & 9.19 \\
\hline & $>250,000$ & 1.97 \\
\hline & $\mathrm{N} / \mathrm{A}$ & 12.69 \\
\hline
\end{tabular}

\section{Data Analysis}

This section first outlines the hypotheses generated from the qualitative study (Section 4.1), followed by quantitative testing of the hypotheses (Section 4.2). 


\subsection{Hypotheses}

Qualitative answers from the semi-structured interviews were analyzed and coded to explore why and how users engaged in specific value co-creation behavior in Mobike (Table 3) [54]. Two independent evaluators familiar with the techniques and research, coded and categorized the responses. Using kappa statistics, the high consistency among coders showed that inter-rater reliability was 0.936 $(p<0.000)$, further ensuring validity [55]. A third researcher handled the coding disagreement till an agreement was reached. We generated four hypotheses $(\mathrm{H} 1, \mathrm{H} 2, \mathrm{H} 3, \mathrm{H} 4)$ related to coded cognitive factors according to coding rules elaborated in Table 3 (Section 4.1.1), and two (H5, H6) related to the time factor (Section 4.1.2), to be elaborated below.

Table 3. Coding enabling factors and categories of participation reporting in Mobike.

\begin{tabular}{|c|c|c|}
\hline Factor Categories & Enabling Factors & Responses \\
\hline \multirow{4}{*}{ Cognitive factors } & Self-efficacy & $\begin{array}{l}\text { Using the rules to remind and educate the other users } \\
\text { Providing assistance through the rules }\end{array}$ \\
\hline & Cognition of duty & $\begin{array}{l}\text { Duty of providing convenience to the next user } \\
\text { Duty of providing help to the system }\end{array}$ \\
\hline & $\begin{array}{l}\text { Company-consumer } \\
\text { identification }\end{array}$ & $\begin{array}{l}\text { The bike and the FFBS service is good } \\
\text { The company does the right thing } \\
\text { Belonging to a same group with other users }\end{array}$ \\
\hline & Anticipated rewards & $\begin{array}{l}\text { Feeling good } \\
\text { Increased credit score }\end{array}$ \\
\hline Time factor & Usage length & Need time to learn and change \\
\hline
\end{tabular}

\subsubsection{Cognitive Factors in Value Co-Creation}

The interview results show that four cognitive factors impact prosumers' value co-creation behavior (classified in Table 4): "self-efficacy", "cognition of duty", "company-consumer identification" and "anticipated rewards". Accordingly, we generated four hypotheses as to how each factor contributes to ensuring trust and responsibility in the sharing economy:

Hypothesis 1 (H1). Self-efficacy has a positive effect on value co-creation.

Self-efficacy is the belief in one's capability to perform a specific task or role necessary to goal attainment [56]. Setting, communicating and maintaining efficacious rules of use is a necessity for successful functioning of a FFBS scheme [47]. In Mobike, although LPS is implanted in every bike, some types of misbehavior cannot be easily detected by the platform's tracking system, such as incorrect parking, which may be crucial for a high-efficiency turnover of the fleet. Thus Mobike encourages users to help report unruly parking by uploading clear photos of the infractions, in order to assist Mobike operators to identify the rule violator, implement penalties and correct the consequences of misbehavior (i.e., repositioning the wrongly parked bike).

Interviewees mentioned that good understanding and abidance of the rules, including adequate reporting, is important for their voluntary and active assistance in Mobike, as the following quotes indicates:

"The rules are clear to me, I know what I can do and how to do it [correct use and the reporting of incorrect use]." 
"I know the rules about how to use the bike and the whole credit score system. So I can communicate with the management team effectively [regarding reporting misbehaviors]."

—34 years old, male, 4 months use of Mobike

In this instance, then, self-efficacy can be represented by the level of confidence Mobike users show in understanding and monitoring the rules and practices of shared mobility to assist the FFBS and to educate misbehaved users towards normative behaviors. We consider self-efficacy to be a positive contributor to active value co-creation because it helps to establish sharing norms and notions of responsibility, trust and reciprocity in the shared economy.

Hypothesis 2 (H2). Cognition of duty has a positive effect on value co-creation.

Cognition of duty refers specifically to who is responsible for reporting misbehavior. In the sharing economy this means that users understand that value co-creation with the firm involves responsibilities on their part to maintain smooth functioning of the shared system. Such responsibilities include innovative roles, such as insuring the convenience of bike access and transfer, indicating the users' cognition of duty to enable the sharing BM through proper consideration and monitoring of fellow users. As indicated by several of the interviewees, these considerations are underpinned by notions of communal trust and reciprocity among users:

"The principle of sharing is to consider the convenience of the next user."

-35 years old, female, 7 months use of Mobike

"It's not only the company's responsibility but everyone using the system [to make sure that rules are implemented]."

-29 years old, male, 7 months use of Mobike

"If the system is in a bad condition, I will be affected when using the bike."

-24 years old, female, 5 months use of Mobike

Data show that active value co-creators find personal relevance with the sharing service and see contributing to the service system as a personal duty [57,58], just communal management of common pool resources may rest on trust and reciprocity between users to avoid so-called tragedies of the commons [59]. Previous studies indicate that under these circumstances, users show more respect and responsibility for shared resources, which can enhance collaborative behavior [35,60]. In the case of Mobike, the cognition of duty motivates interviewees to voluntarily invest their personal time and energy in co-creating the communal value of the FFBS. This kind of psychological investment, according to duty, may function even in the absence of a formal incentive scheme like the Mobike credit system. Mobilization of this sense of duty to uphold and maintain the sharing system from which the user and others benefit ultimately generates a significant influence on the efficacy and functioning of the system [61]. Therefore, we assume that cognition of duty has a positive effect on active value co-creation.

Hypothesis 3 (H3). Company-consumer identification (C-C identification) has a positive effect on value co-creation.

Consumption is a form of identification with the group that comprises the product system. Interviewees expressed their strong identification with the product and service, the company and other users. The following statements from interviews are typical: 
"I love the bike and the service that solves our urgent 'last mile' transport problem, so I will help to maintain the system ... The bike is stylish and high quality, and it is a green mobility, just what I want."

-19 years old, male, 5 months use of Mobike

"I like the company for its innovative ideas. Using its service can show my taste."

-26 years old, male, 6 months use of Mobike

"I'm a 'Mobiker'. I consider myself as belonging to a group of people with similar values, who have influence on my behavior."

—34 years old, male, 4 months use of Mobike

Identification with the firm can be measured using a method to quantify the degree of overlap or similarity between oneself and others in the organizational groups [62-64]. Social identification with groups or organizations can be established to develop or extend one's individual identity. According to marketing literature, consumers often use identification to express their extended self through the symbolic meaning embodied in the brand; and such identification is considered to inspire consumers to protect the brand, the community or the company $[32,65,66]$. Specifically, $\mathrm{C}-\mathrm{C}$ identification in this context is reflected in the relationship between active value co-creators and Mobike, as the interview data show that prosumers are inspired by the mission (green and last-mile transport) and the actual product/service (fashionable bike and convenient usage) of Mobike, as well as the lifestyle it supports (sustainability). Accordingly, they have developed a sense of belonging to the communal identity Mobike represents. We thus assume there is a positive linkage between $C-C$ identification and value co-creation intention [67].

Hypothesis 4 (H4). Anticipated rewards have positive effect on value co-creation.

Once a user reports misbehavior effectively, the system validates the user's assistance and gives reward in the form of a credit prize that encourages users involved in value co-creation. It seems that such a reward motivates people to continue reporting and increase value co-creation, as some of the interviewees indicated:

"If I did reporting, I could get a higher score."

-24 years old, male, 4 months use of Mobike

"Though the credit prize is not high and useless by now, I feel good by getting positive response of my action ... I'm proud of what I do, it's positive energy that the other users will appreciate."

-37 years old, female, 7 months use of Mobike

Some participants see helping the system to identify misbehavior in Mobike like playing a hero's role in a quest game or social drama, so value co-creation behavior brings the rewards of social prestige and the satisfaction of playing and winning a competition for the benefit of society: 
"It is fun and also good for the society."

-28 years old, male, 5 months use of Mobike

"It is like a real AR [Augmented Reality] game. I enjoy it so much!"

-34 years old, male, 4 months use of Mobike

From a socioeconomic perspective, a user can be encouraged to choose a set of preferences to maximize utility $[68,69]$. Value co-creation behavior helps to eliminate dissatisfaction due to defective service and negative reciprocity resulting from other users' misbehaviors, while giving responsible users the opportunity to gain credit and social capital [70-72]. Meanwhile, "gamification" of the credit system is increasingly used by firms to attract users to participate in value co-creation [73]. These rewards that enhance self-satisfaction and a sense of achievement thus encouraging users to participate in value co-creation and sanctioning of other users' devaluing misbehavior. We assume there is a positive relationship between anticipated rewards and active value co-creation.

\subsubsection{Time as a Factor in Value Co-Creation}

Hypothesis 5 (H5). Usage length has a positive effect on value co-creation behavior-the possibility of value co-creation increases over time.

Hypothesis 6 (H6). Value co-creation enabling factors change over time.

Direct observations and interviews further reveal the role of time factor in value co-creation from a holistic perspective. Time is a very important aspect of innovation diffusion [74] as well as social learning and cognitive change [75,76]. Lamberton and Rose [3] argue that prosumers' sharing knowledge takes experience and time to acquire. In our investigation, most interviewees did not display value co-creation behaviors in the initial phase of their joining Mobike, but rather developed it over time. Although the rules are explicitly stated and Mobike encourages users to help report through the mobile app, some users are still confused about participating in value co-creation through the non-face-to-face online system of reporting. As an interviewee mentioned:

"It takes time and encountered experience to understand and implement the rules. [Before a mature understanding] some people are reluctant to do so."

—41 years old, male, 7 months use of Mobike

Therefore, length of usage represents a significant time factor in the transformation towards value co-creation behaviors. Accordingly, users at different phases of incorporation into the FFBS scheme (e.g., early versus mature) may have different cognitive characteristics to enable value co-creation. With time cognitive orientations toward use of the scheme may be enhanced. We thus posit two hypotheses about the time factor, which relates to the learning process (H5) and the interaction with other enabling factors (H6).

Above all, we generate a hypothesis model to elaborate the enabling factors of value co-creation during prosumption processes, as illustrated in Figure 3. 


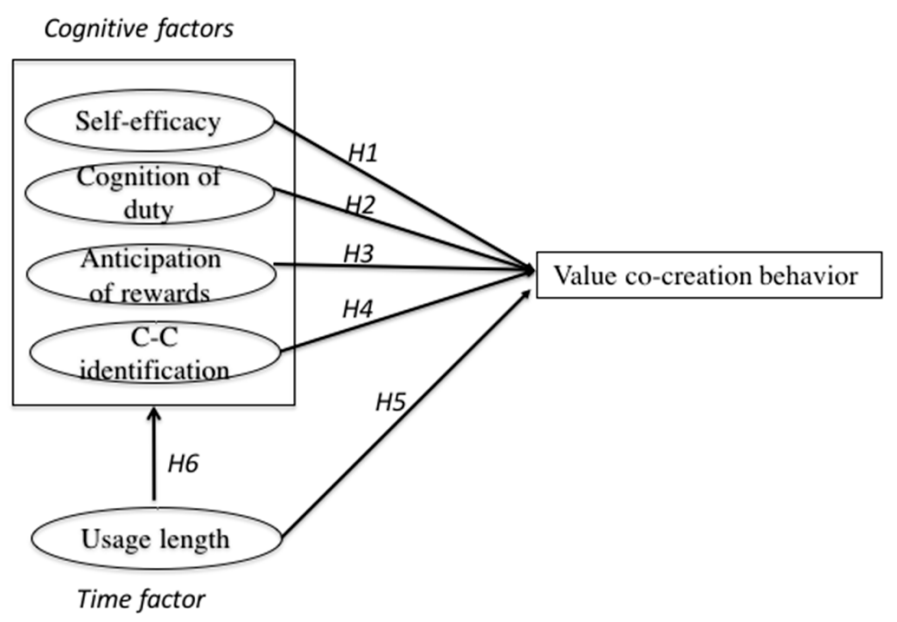

Figure 3. Hypothesis model in the Mobike context.

\subsection{Testing the Hypothesis}

\subsubsection{Measures}

As discussed earlier, the four-section online survey (Table 4) was grounded in the semi-structured interviews as follows:

- Section 1 selects for value co-creation participants by asking the question, "Have you participated in the reporting of bike defects and/or parking violation?" ( $0=$ never, $1=$ yes $)$.

- Section 2 tests H1 (self-efficacy), H2 (cognition of duty), H3 (C-C identification, and H4 (anticipated rewards). All measures were adapted from literature and modified to fit the current study, that asked the respondent to react to designed statements on a 5-point Likert scale from 1 = strongly disagree to 5 = strongly agree $[67,69,77,78]$;

- Section 3 assesses H5 and H6 by asking questions about the respondent's usage length of the Mobike service.

- Section 4 investigates responders' demographic information. The demographic variables (age, gender, education) are selected to control potential effects in hypotheses testing [79].

Exploratory factor analysis of the indicators of the multi-item predictors ("self-efficacy", "C-C identification" and "anticipated rewards") shows discriminate validity, indicating that the factor analysis extracted the three investigated factors appropriately. Cronbach's alpha was employed for the internal consistency of each construct. All the constructs' reliability coefficients are above 0.8, exceeding the acceptable rule of 0.7 [80,81]. The variables' means and standard deviations were also measured (self-efficacy: Cronbach's $\alpha=0.807$, Mean $=3.95, \mathrm{SD}=0.65$; cognition of duty: Mean $=3.28$, $\mathrm{SD}=1.05$; anticipate rewards: Cronbach's $\alpha=0.925$, Mean $=4.26, \mathrm{SD}=0.73 ; \mathrm{C}-\mathrm{C}$ identification: Cronbach's $\alpha=0.935$, Mean $=3.87, \mathrm{SD}=0.75)$. Meanwhile, there was no evidence that correlations created serious multi-collinearity since all the variance inflation factors were below 2.0 [82]. 
Table 4. Description of variables and questions.

\begin{tabular}{|c|c|}
\hline Independent Variables & Questions/Items/Scales \\
\hline \multicolumn{2}{|l|}{ Predictor variables } \\
\hline H1. Self-efficacy [77] & $\begin{array}{l}\text { I have competence in assistance. } \\
\text { I have competence dealing with the problems. } \\
\text { I can affect other users' behavior. }\end{array}$ \\
\hline H2. Cognition of duty [78] & In my opinion, users have duty to provide assistance to the system. \\
\hline H3. C -C identification [67] & $\begin{array}{l}\text { I am somewhat associated with Mobike. } \\
\text { I have a sense of connection with Mobike. } \\
\text { I consider myself as belonging to the group of people who are in favour of Mobike. } \\
\text { Customers of Mobike are probably similar to me. } \\
\text { Employees of Mobike are probably similar to me. } \\
\text { Mobike shares my values. } \\
\text { Being a customer of Mobike is part of my sense of who I am. } \\
\text { Using Mobike will help me express my identity. }\end{array}$ \\
\hline H4. Anticipation of rewards [69] & $\begin{array}{l}\text { I will receive rewards in return for my report. } \\
\text { I will receive a good feeling in return for my report. }\end{array}$ \\
\hline H5 and 6. Usage length & $\begin{array}{l}\text { How long have you used the bike-sharing system? } \\
\text { Range from } 1=\text { " }<1 \text { month" to } 4=\text { "> } 6 \text { months". }\end{array}$ \\
\hline \multicolumn{2}{|l|}{ Control variables } \\
\hline $\begin{array}{l}\text { Gender } \\
\text { Age } \\
\text { Education }\end{array}$ & $\begin{array}{c}\qquad=\text { Female, } 1=\text { Male. } \\
\text { Range from } 1=" 16-18 " \text { to } 7=\text { " }>60 " . \\
\text { Range from } 1=\text { "Up to secondary school" to } 4=\text { "Graduate degree". }\end{array}$ \\
\hline
\end{tabular}

\subsubsection{Results}

To determine the influencing factors, a logit regression was employed to assess the respondents' active value co-creation behavior.

In Table 5, we first added the cognitive variables in Model 1, then added the time factor in Model 2 and the control variables in Model 3. As predicted (see Model 3), the regression results support H1 (self-efficacy: $\beta=0.54, p<0.05$ ), $\mathrm{H} 2$ (cognition of duty: $\beta=0.294, p<0.01$ ), H4 (anticipated rewards: $\beta=0.314, p<0.10$ ) and H5 (usage length: $\beta=1.097, p<0.01$ ). However, $C-C$ identification was not significant in this context $(p>0.10)$, so H3 is not supported. Self-efficacy, cognition of duty, anticipated rewards and usage length made significant contribution to the value co-creation behavior under the control variables to a satisfactory degree (Nagelkerke's $R^{2}=0.448$ ). The possibility of value co-creation shows an increasing trend over time, providing further support for $\mathrm{H} 5$. The regression results were robust in the models with or without control variables.

Table 5. Regression Results.

\begin{tabular}{|c|c|c|c|c|c|c|}
\hline \multirow{2}{*}{ Independent Variables } & \multicolumn{2}{|c|}{ Model 1} & \multicolumn{2}{|c|}{ Model 2} & \multicolumn{2}{|c|}{ Model 3} \\
\hline & B & Wald & B & Wald & B & Wald \\
\hline H1. Self-efficacy & $0.531^{* *}$ & 5.341 & $0.555 * *$ & 4.601 & $0.54 * *$ & 4.024 \\
\hline H2.Cognition of duty & $0.438^{* * *}$ & 19.022 & $0.325^{* * *}$ & 8.715 & $0.294^{* * *}$ & 6.697 \\
\hline H3.C -C Identification & 0.115 & 0.446 & 0.037 & 0.038 & -0.117 & 0.318 \\
\hline H4. Anticipated rewards & $0.58^{* * *}$ & 10.367 & $0.414^{* *}$ & 4.144 & $0.314 *$ & 2.832 \\
\hline H5. Usage length & & & $1.095^{* * *}$ & 74.75 & $1.097^{* * *}$ & 69.207 \\
\hline \multicolumn{7}{|l|}{ Control Variables } \\
\hline Age & & & & & $-0.289 * *$ & 6.132 \\
\hline Gender & & & & & 0.189 & 0.592 \\
\hline Education & & & & & -0.287 & 1.483 \\
\hline Nagelkerke's $\mathrm{R}^{2}$ & 0.184 & & 0.404 & & 0.448 & \\
\hline
\end{tabular}

Note: ${ }^{* * *} p<0.01 ;{ }^{* *} p<0.05 ;{ }^{*} p<0.10 ; n=457$. 
To test $\mathrm{H} 6$, we separated the samples into four groups deliberately to find the enabling factors in term of usage length. The regression results (Table 6) supported H6 that different enabling factors affected the value co-creation behavior in different using stages. Below 1 month, there was no significant factor enabling this value co-creation. As time passed by, anticipated rewards worked during the period of 1-3 months. Later on during the 4-6 months period, self-efficacy and cognition of duty became the significant factors. Moreover, those who had been using Mobike for over 6 months and had stronger cognition of duty, show a significantly higher possibility of value co-creation.

Table 6. Regression Results in different using stages.

\begin{tabular}{|c|c|c|c|c|c|c|c|c|}
\hline \multirow{2}{*}{$\begin{array}{c}\text { Independent } \\
\text { Variables }\end{array}$} & \multicolumn{2}{|c|}{ Below 1 Month $n=106$} & \multicolumn{2}{|c|}{ 1-3 Months $n=123$} & \multicolumn{2}{|c|}{ 4-6 Months $n=136$} & \multicolumn{2}{|c|}{ Above 6 Months $n=92$} \\
\hline & B & Wald & B & Wald & B & Wald & B & Wald \\
\hline Self-efficacy & 0.404 & 0.393 & 0.022 & 0.002 & $0.999 *$ & 2.831 & 0.692 & 1.017 \\
\hline C-C Identification & -0.034 & 0.007 & -0.094 & 0.07 & -0.279 & 0.289 & 0.295 & 0.148 \\
\hline Anticipated rewards & 0.616 & 1.252 & $0.612 *$ & 3.053 & -0.34 & 0.376 & 0.365 & 0.369 \\
\hline Gender & 0.878 & 2.471 & 0.324 & 0.593 & -0.472 & 0.58 & 0.02 & 0.001 \\
\hline Education & 0.347 & 0.187 & $-0.954^{* *}$ & 5.678 & 0.097 & 0.031 & 0.34 & 0.3 \\
\hline Nagelkerke's R ${ }^{2}$ & 0.148 & & 0.178 & & 0.411 & & 0.303 & \\
\hline
\end{tabular}

\section{Discussion}

This section will first discuss two kinds of enabling factors of value co-creation behavior in the case of Mobike - cognitive factors (Section 5.1.1) and time factors (Section 5.1.2)—and how firms can leverage them in sharing BMs. Building on this, we propose a framework of value co-creation between prosumers and firms/organizations in the sharing economy, and explore its implications for social innovation (Section 5.2).

\subsection{Enabling Factors for Value Co-Creation}

\subsubsection{The Cognitive Factors}

As Table 5 shows, and consistent with previous studies, the level of prosumers' self-efficacy (H1), cognition of duty (H2) and anticipated rewards (H4) positively contribute to active value co-creation behaviors in the FFBS. This has the following implications in the wider O2O sharing economy:

1. Most sharing BMs are based on carefully crafted and adjustable rules, empowering frequent and timely interactions between users and the value co-creation system. The service providers normally assume that users understand the rules and follow them, even though a system of penalties is also set to remind and educate people [33]. Our data show that prosumers' self-efficacy about the rules of the scheme varies, which has a corresponding impact on their possibility and degree of value co-creation. Firms should actively encourage and empower value co-creation by helping prosumers build self-efficacy in relation to the rules of the sharing scheme, and by making such rules and the systemic impacts of rule-oriented behavior as comprehensible as possible.

2. Both the qualitative and quantitative data suggest that a milestone between passive prosumption and active value co-creation exists and correlates to the level of cognition of duty. Active prosumers consider themselves as an important component of the BM and its positive social implications, therefore invest time learning the rules quickly and join peer groups in order to be able to provide valid reporting assistance to the system. In other words, while the rules set the context, the development of duty cognition provides inner drivers to transform passive prosumers into active value co-creators. 
3. Anticipated rewards are necessary to sustain prosumers' value co-creation behavior. The sense of personal responsibility within a cultural milieu may inspire people towards self-transcending actions like value co-creation, yet some expected rewards are important to incentivize prosumers to continue such behavior. As our data show, rewards can take different forms. Some are in the form of credit in the scoring system; some are in the form of enjoyment (e.g., the excitement of playing virtual reality games for some Mobike users). A engaged, nuanced and reciprocal nuanced approach is required from the firm to understand the needs of different user groups and to ensure the rewards are appropriate and lead to desirable value co-creation.

In contrast to previous studies that suggest a higher level of $\mathrm{C}-\mathrm{C}$ identification contributes to more value co-creation behaviors [64,83], our empirical data do not show a significant relationship in the case of Mobike. In fact, while in stage 1 most of interviewees showed high C-C identification with the Mobike company, the levels of $\mathrm{C}-\mathrm{C}$ identification of respondents in stage 2 has no essential difference despite their much more diverse levels of involvement in value co-creation activities. A possible reason for this finding might be that FFBS was still a novel phenomenon in China when we conducted the online survey (December 2016). Before its start in April 2016, there were hundreds of public bike-sharing systems launched by Chinese local governments. Though public bike-sharing systems are cheap and green, they had come under heavy criticism for their inconvenient fixed stations and tedious registration processes. FFBS, as a form of social innovation, provides green and convenient transport, contributing to the solution of the city's "last mile" problem, so to some extent it appeals to people who have daily transport demands, leading to a high and homogeneous C-C identification in a short time period. Similarly, Mobike bikes' novelty and quality sparked huge excitement and followership among users within a few months. In addition, the Mobike marketing team invested smartly in a social media campaign to build $\mathrm{C}-\mathrm{C}$ identification, which might also contribute to the observed high level of $\mathrm{C}-\mathrm{C}$ identification in respondents.

In other words, it is possible that as the Mobike BM and user groups mature, the $\mathrm{C}-\mathrm{C}$ identification will also be adjusted to reflect a positive relationship with value co-creation behaviors, as previous studies have suggested. Our results suggest that during the early development phase of a disruptive $\mathrm{O} 2 \mathrm{O}$ sharing business, a high level of $\mathrm{C}-\mathrm{C}$ identification does not necessarily contribute to more active and voluntary value co-creation behaviors. In contrast, self-efficacy, cognition of duty and anticipated rewards seem to have direct relevance in encouraging and empowering prosumers' active value co-creation.

\subsubsection{The Time Factor}

As Table 5 shows, usage length in the sharing system is closely related to transforming prosumers to active value co-creators, showing a strong learning process. Meanwhile, Table 6 shows that different enabling factors occur during different user stages which can be demarcated in terms of the formation of an active value co-creator as follows:

- $\quad$ the latent period (below 1 month);

- the rising period (1-3 months);

- the formative period (4-6 months);

- the stable period (more than 6 months).

In the latent period, no cognitive enabling factor is significant. In the rising period, the rate of value co-creation behavior rises dramatically from $17.92 \%$ to $57.72 \%$ in our survey, and anticipated rewards turns out to be the most salient enabling factor. The next phase witnesses the formation of value co-creation capacity especially the self-efficacy and cognition of duty. Consistent with the findings above, C-C identification is not significant even in the formative and mature period, and thus does not appear to be transformative in engendering stronger value co-creation behavior.

The time factor also shows that the trust and reciprocity that is necessary to maintain effective management of common pool resources [84] takes time to develop for users in a sharing community. 
While Mobike goods (bikes) are private, the service relies on public goods (public, accessible and well maintained parking and road resources), which are, in effect, common resources. The value co-creation behavior of prosumers helps to prevent a tragedy of the commons, although a learning process is required to achieve that.

\subsection{A Proposed Value Co-Creation Framework in the Sharing Economy}

The above discussion shows that prosumers in the sharing BMs are embedded in a continuous micro social learning and innovation process-indeed, sharing business organizations need to develop a system that supports value co-creation in the first place, yet it requires users' active responses towards value propositions to function, as well as to maintain and improve the sharing system. In other words, prosumers' active value co-creation is key to enabling sharing BMs to realize their social innovation potential in providing more adequate and low-carbon transport as in the case of Mobike. Multiple factors are required to enable such value co-creation behaviors. First, prosumers in the system need time to learn the rules, including social sharing values that underpinned them, and to gain experience, in order to participate in the value co-creation activities. Second, the learning process enables cognitive changes of prosumers, especially the senses of duty and fidelity to the sharing system, but also their motivation to respond to behaviors that undermine the system, which finally encourages and consolidates their value co-creation behaviors.

As illustrated in Figure 4, along with the sharing economy expanding into more and more crucial arenas of urban life, such as mobility, accommodation and food, different kinds of social innovations are inspired to fulfill the sustainable potential of the sharing economy on the one hand, and to remedy side-effects of this disruptive technological and commercial force such as misbehavior in the case of Mobike, on the other. Through value co-creation activities between participants/prosumers and sharing firms/organizations, a continuous learning process may enable positive cognitive change. Ultimately, the social innovations are consolidated through continued value co-creation, leading to new behaviors and institutions that result in a better and more sustainable sharing environment and urban life.

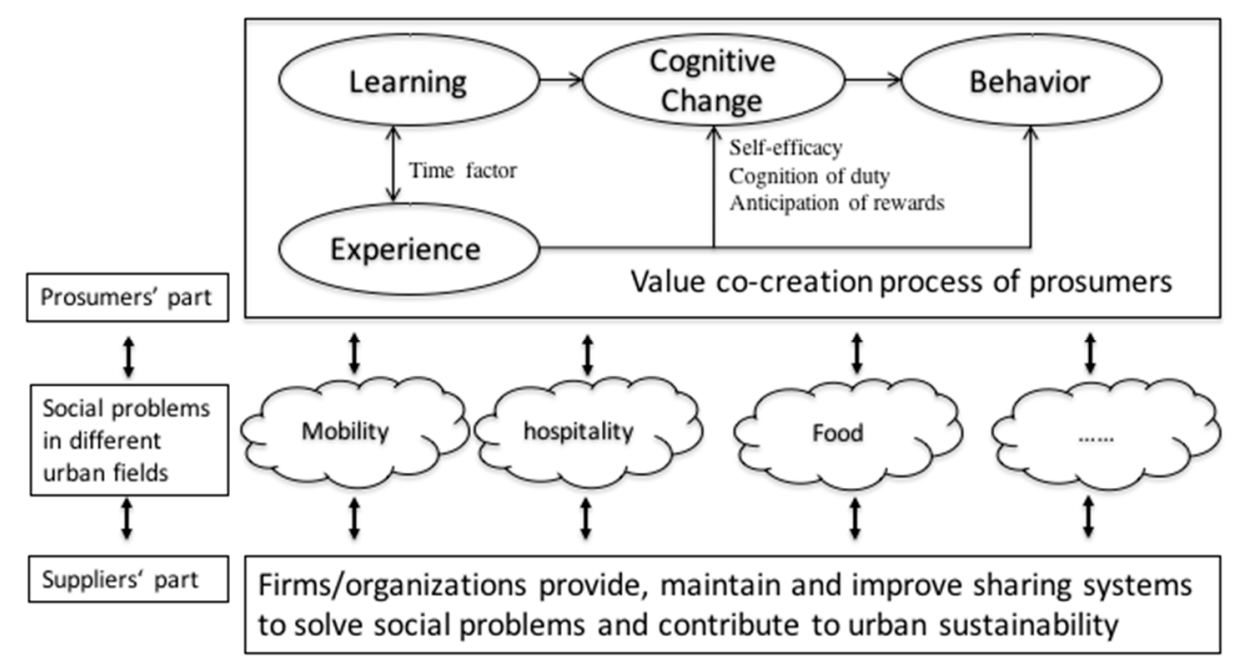

Figure 4. Proposed value co-creation framework in the sharing economy in urban contexts.

\section{Conclusions}

Our research represents one of the first scholarly attempts to investigate enabling factors in the process of value co-creation between prosumers and firms of sharing systems, using a mixed method approach. It makes key contributions to this emerging scholarship:

First, we argue that emergent value co-creation behaviors in the sharing economy should be identified and encouraged in order to fully realize sustainable opportunities in the sharing business. 
It is crucial to acknowledge and consolidate prosumers' value co-creation as a contribution to respective sharing BMs in order to better strategize these valuable resources for both commercial and public goods (e.g., providing stable, high-quality and clean daily transport modes).

Second, this paper is among the first quantitative studies to demonstrate significantly positive relationships between factors like "self-efficacy", "cognition of duty" and "anticipated rewards" with value co-creation behavior in the sharing economy. Our analysis demonstrates that not only equipping prosumers with comprehensive and effective value co-creation rules should be in place, but also that the cognition of duty for value co-creation is important to transform passive rule conformers to active value contributors. Adequate and customized rewards are also important to sustain value co-creation behaviors.

Third, the time factor is brought into consideration of enabling value co-creation, evidenced by the fact that the longer users stay in the sharing system, the higher the possibility of them being active value co-creators. The results suggest a clear learning process of prosumers in the sharing business which can be leveraged by firms and wider societies in order to shape a better sharing environment to realise sustainable potentials of the emerging sharing economy.

Last but not least, the paper proposes a framework to illustrate prosumers' value co-creation processes with firms/organizations in the sharing economy. Contrary to the limited producer-consumer interaction spaces in the traditional BMs, in app-based sharing businesses users interact with multiple and overlapping phases of the prosumption processes thanks to the empowerment of ICT and changing socioeconomic relationships in cities. The more intimate connection between users and firms can enable restructuring of the relationship between users, the shared objects and the sharing platform towards a more integrated communal system based not only on price and personal convenience but also shared sustainability norms, trust, and social responsibility. Value co-creation acts as the main action field for forming and sustaining this fast-changing relationship. As our case study shows, active value co-creation between prosumers and firms is essential in maintaining the $\mathrm{O} 2 \mathrm{O}$ sharing system and may even determine its success or failure.

It should be stressed that some of the enabling factors we identified, such as the cognition of duty could be culturally dependent, which requires further research across different cultural, political and socio-economic contexts that is beyond the scope of this paper. Nevertheless, by building on this single case study, future research may investigate more common enabling factors in different sharing contexts, and explore the possible mechanisms to support active value co-creation behaviors in the sharing economy which may encourage and foster further social innovations towards sustainability in cities and beyond. Our results thus have implications not only for how to regulate, enhance and sustain the evolving app-based sharing economy, but also for how to significantly reduce environmental impacts, such as $\mathrm{CO}_{2}$ emissions, that come when people eschew win-win opportunities to share mobility resources, such as cars and bikes, due to lack of trust, reciprocity and other barriers to value co-creation.

Acknowledgments: This research is supported by EU Horizon 2020 GREEN-WIN Project (642018) and Tongji University Postgraduate Overseas Exchange Scholarship (2017010010).

Author Contributions: J.L. and Y.M. conceived and designed the mixed method research; J.L. performed the interviews and online survey; J.L. and Y.M. analyzed the data and wrote the initial paper; D.Z., D.M. and T.T. oversaw the research and project funding and contributed ideas and revisions to subsequent iterations of the article.

Conflicts of Interest: The authors declare no conflict of interest.

\section{References}

1. Belk, R. You are what you can access: Sharing and collaborative consumption online. J. Bus. Res. 2014, 67, 1595-1600. [CrossRef]

2. Botsman, R.; Rogers, R. What's Mine Is Yours: The Rise of Collaborative Consumption; HarperCollins: New York, NY, USA, 2010. 
3. Lamberton, C.P.; Rose, R.L. When is ours better than mine? A framework for understanding and altering participation in commercial sharing systems. Soc. Sci. Electron. Publ. 2012, 76, 109-125. [CrossRef]

4. John, N.A. The social logics of sharing. Commun. Rev. 2013, 16, 113-131. [CrossRef]

5. Kathan, W.; Matzler, K.; Veider, V. The sharing economy: Your business model's friend or foe? Bus. Horiz. 2016, 59, 663-672. [CrossRef]

6. Cohen, B.D.; Kietzmann, J. Ride on! Mobility business models for the sharing economy. Organ. Environ. 2014, 27, 279-296. [CrossRef]

7. Agyeman, J.; Mclaren, D. Sharing Cities: A Case for Truly Smart and Sustainable Cities; MIT Press: Cambridge, MA, USA, 2015.

8. Sundararajan, A. The Sharing Economy: The End of Employment and the Rise of Crowd-Based Capitalism; MIT Press: Cambridge, MA, USA, 2016.

9. Schaefers, T.; Lawson, S.J.; Kukar-Kinney, M. How the burdens of ownership promote consumer usage of access-based services. Mark. Lett. 2016, 27, 569-577. [CrossRef]

10. Lawson, S.J.; Gleim, M.R.; Perren, R.; Hwang, J. Freedom from ownership: An exploration of access-based consumption. J. Bus. Res. 2016, 69, 2615-2623. [CrossRef]

11. Martin, C.J.; Upham, P.; Budd, L. Commercial orientation in grassroots social innovation: Insights from the sharing economy. Ecol. Econ. 2015, 118, 240-251. [CrossRef]

12. Cohen, B.; Muñoz, P. Sharing cities and sustainable consumption and production: Towards an integrated framework. J. Clean. Prod. 2016, 134, 87-97. [CrossRef]

13. Rayna, T. Understanding the challenges of the digital economy: The nature of digital goods. Commun. Strateg. 2010, 1, 13-36. [CrossRef]

14. Rifkin, J. The Zero Marginal Cost Society; St. Martin's Griffin: New York, NY, USA, 2014.

15. Botsman, R. The Sharing Economy Lacks a Shared Definition. Available online: https:/ /www.fastcoexist. com/3022028/the-sharing-economy-lacks-a-shared-definition (accessed on 28 February 2017).

16. Ritzer, G. Prosumption: Evolution, revolution, or eternal return of the same? J. Consum. Cult. 2014, 14, 3-24. [CrossRef]

17. Joore, P.; Han, B. A multilevel design model: The mutual relationship between product-service system development and societal change processes. J. Clean. Prod. 2015, 97, 92-105. [CrossRef]

18. Ritzer, G. The "new" world of prosumption: Evolution, "return of the same," or revolution? Sociol. Forum 2015, 30, 1-17. [CrossRef]

19. Toffler, A. The Third Wave; Bantam Books: New York, NY, USA, 1981.

20. Brodie, R.J.; Ilic, A.; Juric, B.; Hollebeek, L. Consumer engagement in a virtual brand community: An exploratory analysis. J. Bus. Res. 2013, 66, 105-114. [CrossRef]

21. Ritzer, G.; Jurgenson, N. Production, consumption, prosumption: The nature of capitalism in the age of the digital prosumer. J. Consum. Cult. 2010, 10, 13-36. [CrossRef]

22. Eden, S. Blurring the boundaries: Prosumption, circularity and online sustainable consumption through freecycle. J. Consum. Cult. 2015, 1-21. [CrossRef]

23. Bellekom, S.; Arentsen, M.; Gorkum, K.V. Prosumption and the distribution and supply of electricity. Energy Sustain. Soc. 2016, 6, 22. [CrossRef]

24. Vargo, S.L.; Lusch, R.F. Evolving to a new dominant logic for marketing. J. Mark. 2004, 68, 1-17. [CrossRef]

25. Prahalad, C.K.; Ramaswamy, V. Co-creation experiences: The next practice in value creation. J. Interact. Mark. 2004, 18, 5-14. [CrossRef]

26. Payne, A.F.; Storbacka, K.; Frow, P. Managing the co-creation of value. J. Acad. Mark. Sci. 2008, 36, 83-96. [CrossRef]

27. Vargo, S.L.; Lusch, R.F. From goods to service(s): Divergences and convergences of logics. Ind. Mark. Manag. 2008, 37, 254-259. [CrossRef]

28. Bo, E.; Tronvoll, B.; Gruber, T. Expanding understanding of service exchange and value co-creation: A social construction approach. J. Acad. Mark. Sci. 2011, 39, 327-339. [CrossRef]

29. Rayna, T.; Striukova, L. Involving consumers: The role of digital technologies in promoting 'prosumption' and user innovation. J. Knowl. Econ. 2016, 1-20. [CrossRef]

30. Celata, F.; Hendrickson, C.Y.; Sanna, V.S. The sharing economy as community marketplace? Trust, reciprocity and belonging in peer-to-peer accommodation platforms. Camb. J. Reg. Econ. Soc. 2017, 10, 349-363. [CrossRef] 
31. Fullerton, R.A.; Punj, G. Repercussions of promoting an ideology of consumption: Consumer misbehavior. J. Bus. Res. 2004, 57, 1239-1249. [CrossRef]

32. Schaefers, T.; Wittkowski, K.; Benoit, S.; Ferraro, R. Contagious effects of customer misbehavior in access-based services. J. Serv. Res. 2015, 19. [CrossRef]

33. Bardhi, F.; Eckhardt, G.M. Access-based consumption: The case of car sharing. J. Consum. Res. 2012, 39, 881-898. [CrossRef]

34. Cannon, B.; Chung, H. A framework for designing co-regulation models well-adapted to technology-facilitated sharing economies. Santa Clara High Technol. Law J. 2015, 31, 23-96.

35. Hartl, B.; Hofmann, E.; Kirchler, E. Do we need rules for "what's mine is yours"? Governance in collaborative consumption communities. J. Bus. Res. 2016, 69, 2756-2763. [CrossRef]

36. Belk, R. Sharing. J. Consum. Res. 2010, 36, 715-734. [CrossRef]

37. Hertler, K.; Tasso, N. Dare to Share: User Value Co-Creation in the Sharing Economy. Master's Thesis, Lund University, Lund, Sweden, 2 June 2015.

38. Edbring, E.G.; Lehner, M.; Mont, O. Exploring consumer attitudes to alternative models of consumption: Motivations and barriers. J. Clean. Prod. 2016, 123, 5-15. [CrossRef]

39. Ravenelle, A.J. Sharing economy workers: Selling, not sharing. Camb. J. Reg. Econ. Soc. 2017, 10, $281-295$. [CrossRef]

40. Schor, J.B. Does the sharing economy increase inequality within the eighty percent? Findings from a qualitative study of platform providers. Camb. J. Reg. Econ. Soc. 2017, 10, 263-279. [CrossRef]

41. Srnicek, N. Platform Capitalism; Polity Press: Cambridge, UK, 2017.

42. Standing, G. The Corruption of Capitalism: Why Rentiers Thrive and Work Does Not Pay; Biteback Publishing: London, UK, 2016.

43. Ma, Y.; Rong, K.; Mangalagiu, D.; Thornton, T.F.; Zhu, D. Co-evolution between urban sustainability and business ecosystem innovation: Evidence from the sharing mobility sector in Shanghai. J. Clean. Prod. 2017, in press.

44. Valencia Cardona, A.; Mugge, R.; Schoormans, J.P.; Schifferstein, H.N. Characteristics of Smart PSSs: Design Considerations for Value Creation. In Proceedings of the CADMC 2013: 2nd Cambridge Academic Design Management Conference, Cambridge, UK, 4-5 September 2013.

45. Stake, R.E. The Art of Case Study Research; Sage Publications: Thousand Oaks, CA, USA, 1995.

46. Flyvbjerg, B. Five Misunderstandings about Case-Study Research. Qual. Inq. 2006, 12, 219-245. [CrossRef]

47. Shaheen, S.A.; Guzman, S.; Zhang, H. Bikesharing in Europe, the Americas, and Asia: Past, present, and future. Transp. Res. Rec. J. Transp. Res. Board 2010, 2143, 159-167. [CrossRef]

48. Fishman, E. Bikeshare: A review of recent literature. Transp. Rev. 2016, 36, 92-113. [CrossRef]

49. Ljungblad, S. Openbike: The design craft of future bike sharing. In Proceedings of the Crafting the Future European Academy of Design Conference, Göteborg, Sweden, 17-19 April 2013.

50. Reiss, S.; Paul, F.; Bogenberger, K. Empirical analysis of munich's free-floating bike sharing system: Gps-booking data and customer survey among bikesharing users. In Proceedings of the Transportation Research Board Annual Meeting, Washington, DC, USA, 11-15 September 2015.

51. Chagnon, K. America's bike-share programs. Bicycling, 9 September 2011.

52. Gioia, D.A.; Corley, K.G.; Hamilton, A.L. Seeking qualitative rigor in inductive research. Organ. Res. Methods 2013, 16, 15-31. [CrossRef]

53. Bernard, H.R. Research Methods in Anthropology: Qualitative and Quantitative Approaches, 2nd ed.; Sage Publications: Thousand Oaks, CA, USA, 1996.

54. Saldaña, J. The Coding Manual for Qualitative Researchers; Sage Publications: Los Angeles, CA, USA, 2009.

55. Landis, J.R.; Koch, G.G. The measurement of observer agreement for categorical data. Biometrics 1977, 159-174. [CrossRef]

56. Gist, M.E. Self-efficacy: Implications for organizational behavior and human resource management. Acad. Manag. Rev. 1987, 12, 472-485. [CrossRef]

57. Zaichkowsky, J.L. Measuring the involvement construct. J. Consum. Res. 1985, 12, 341-352. [CrossRef]

58. Zaichkowsky, J.L. Conceptualizing involvement. J. Advert. 1986, 15, 4-34. [CrossRef]

59. Habibi, M.R.; Kim, A.; Laroche, M. From sharing to exchange: An extended framework of dual modes of collaborative nonownership consumption. J. Assoc. Consum. Res. 2016, 1, 277-294. [CrossRef]

60. Ostrom, E. Governing the Commons; Cambridge University Press: Cambridge, UK, 1990. 
61. Hollebeek, L.D.; Brodie, R.J. Wine service marketing, value co-creation and involvement: Research issues. Int. J. Wine Bus. Res. 2009, 21, 339-353. [CrossRef]

62. Ashforth, B.E.; Mael, F. Social identity theory and the organization. Acad. Manag. Rev. 1989, 14, $20-39$. [CrossRef]

63. Ashforth, B.E.; Harrison, S.H.; Corley, K.G. Identification in organizations: An examination of four fundamental questions. J. Manag. 2008, 34, 325-374. [CrossRef]

64. Bagozzi, R.P.; Bergami, M.; Marzocchi, G.L.; Morandin, G. Customer-organization relationships: Development and test of a theory of extended identities. J. Appl. Psychol. 2012, 97, 63. [CrossRef] [PubMed]

65. Cardador, M.T.; Pratt, M.G. Identification management and its bases: Bridging management and marketing perspectives through focus on affiliation dimensions. J. Acad. Mark. Sci. 2006, 34, 174-184. [CrossRef]

66. Rindfleisch, A.; Burroughs, J.E.; Wong, N. The safety of objects: Materialism, existential insecurity, and brand connection. J. Consum. Res. 2008, 36, 1-16. [CrossRef]

67. Einwiller, S.A.; Fedorikhin, A.; Johnson, A.R.; Kamins, M.A. Enough is enough! When identification no longer prevents negative corporate associations. J. Acad. Mark. Sci. 2006, 34, 185-194. [CrossRef]

68. Smelser, N.; Swedberg, R. Handbook of economic sociology. Eur. J. Mark. 1994, 47, 705-706. [CrossRef]

69. Bock, G.W.; Zmud, R.W.; Kim, Y.G.; Lee, J.N. Behavioral intention formation in knowledge sharing: Examining the roles of extrinsic motivators, social-psychological factors, and organizational climate. MIS Q. 2005, 29, 87-111. [CrossRef]

70. Sahlins, M. Stone Age Economics, 2nd ed.; Routledge: London, UK, 2004.

71. Habibi, M.R.; Davidson, A.; Laroche, M. What managers should know about the sharing economy. Bus. Horiz. 2017, 60, 113-121. [CrossRef]

72. Ferrari, M.Z. Beyond uncertainties in the sharing economy: Opportunities for social capital. Eur. J. Risk Regul. 2016, 7, 664-674. [CrossRef]

73. Huotari, K.; Hamari, J. Defining Gamification: A Service Marketing Perspective. In Proceedings of the International Academic Mindtrek Conference, Tampere, Finland, 3-5 October 2012; pp. 17-22. [CrossRef]

74. Rogers, E.M. A diffusion of innovations. J. Contin. Educ. Health Prof. 1963, 17, 62-64. [CrossRef]

75. Bandura, A.; Walters, R.H. Social learning and personality development. Am. Sociol. Rev. 1963, $23,634-635$. [CrossRef]

76. Vergragt, P.J.; Brown, H.S. Sustainable mobility: From technological innovation to societal learning. J. Clean. Prod. 2007, 15, 1104-1115. [CrossRef]

77. Schwarzer, R.; Born, A. The assessment of optimistic self-beliefs: Comparison of the Chinese, Indonesian, Japanese, and Korean versions of the general self-efficacy scale. Psychologia 1997, 40, 1-13.

78. Meuter, M.L.; Bitner, M.J.; Ostrom, A.L.; Brown, S.W. Choosing among alternative service delivery modes: An investigation of customer trial of self-service technologies. J. Mark. 2005, 69, 61-83. [CrossRef]

79. Akbar, P.; Mai, R.; Hoffmann, S. When do materialistic consumers join commercial sharing systems. J. Bus. Res. 2016, 69, 4215-4224. [CrossRef]

80. Nunnally, N.R. Stream renovation: An alternative to channelization. Environ. Manag. 1978, 2, $403-411$. [CrossRef]

81. Karim Ghani, W.A.; Rusli, I.F.; Biak, D.R.; Idris, A. An application of the theory of planned behaviour to study the influencing factors of participation in source separation of food waste. Waste Manag. 2013, 33, 1276-1281. [CrossRef] [PubMed]

82. Stine, R.A. Graphical interpretation of variance inflation factors. Am. Stat. 1995, 49, 53-56. [CrossRef]

83. Ahearne, M.; Bhattacharya, C.B.; Gruen, T. Antecedents and consequences of customer-company identification: Expanding the role of relationship marketing. J. Appl. Psychol. 2005, 90, 574-585. [CrossRef] [PubMed]

84. Ostrom, E. Background on the institutional analysis and development framework. Policy Stud. J. 2011, 39, 7-27. [CrossRef]

(c) 2017 by the authors. Licensee MDPI, Basel, Switzerland. This article is an open access article distributed under the terms and conditions of the Creative Commons Attribution (CC BY) license (http:// creativecommons.org/licenses/by/4.0/). 